\title{
Analysis of sintering behavior of silicon nitride based on master sintering curve theory of liquid phase sintering
}

\author{
Junichi TATAMI, ${ }^{\dagger}$ Daisuke HIRATSUKA, Shigefumi OKADA, Katsutoshi KOMEYA and Toru WAKIHARA
}

Graduate School of Environment and Information Sciences, Yokohama National University, 79-7 Tokiwadai, Hodogayaku, Yokohama 240-8501, Japan

\begin{abstract}
We propose a new master sintering curve (MSC) theory for liquid phase sintering in consideration of grain rearrangement and solution-precipitation in order to analyze the sintering behaviors of silicon nitride $\left(\mathrm{Si}_{3} \mathrm{~N}_{4}\right)$ powder compacts. We found that the MSC for liquid phase sintering is theoretically the same expression as that for solid-state sintering. Very fine high-purity powders of $\mathrm{Si}_{3} \mathrm{~N}_{4} \mathrm{Y}_{2} \mathrm{O}_{3}, \mathrm{Al}_{2} \mathrm{O}_{3}, \mathrm{AIN}$, and $\mathrm{TiO}_{2}$ were used as the raw materials to make powder compacts. The degree of sintering shrinkages of the powder compacts, which contained different amounts of the sintering aids, were measured directly by the laser displacement measurement method using a dilatometer. Based on the displacements and the specimen dimensions, the shrinkage ratios and rates could be calculated. The sintering shrinkage behavior depended on the sintering aid used and the heating rate. The MSCs were obtained for shrinkage ratios of $0-2$ and 2-15\% corresponding to grain rearrangement and the solutionprecipitation process, respectively. Finally, the apparent activation energies of sintering of $\mathrm{Si}_{3} \mathrm{~N}_{4}$ for grain rearrangement and the solution-precipitation process were found to be 251-294 and 345-430 kJ/mol, respectively, depending on the sintering aid used. (๑2016 The Ceramic Society of Japan. All rights reserved.
\end{abstract}

Key-words : Silicon nitride, Liquid phase sintering, Master sintering curve, Grain rearrangement, Solution-precipitation

[Received November 19, 2015; Accepted December 30, 2015]

\section{Introduction}

Silicon nitride $\left(\mathrm{Si}_{3} \mathrm{~N}_{4}\right)$ ceramics have excellent mechanical properties, such as high strength and toughness. ${ }^{1-11)}$ As a result, they are used in glow plugs, cutting tools, bearings, and turbocharger rotors, among other devices. ${ }^{12)-14)} \mathrm{Si}_{3} \mathrm{~N}_{4}$ itself is difficult to densify, owing to its low self-diffusion coefficient. ${ }^{15)}$ Therefore, dense $\mathrm{Si}_{3} \mathrm{~N}_{4}$ ceramics are fabricated through liquid phase sintering, which involves the addition of sintering aids, such as $\mathrm{Y}_{2} \mathrm{O}_{3}$ and $\mathrm{Al}_{2} \mathrm{O}_{3}$. ${ }^{16), 17)}$ The densification of $\mathrm{Si}_{3} \mathrm{~N}_{4}$ through liquid phase sintering occurs because of the grain rearrangement by the formation of the liquid phase and by the solution-precipitation process, which is controlled by interfacial reactions or by the diffusion of atoms or ions in the liquid phase as well as in the other materials. ${ }^{18)-21)}$ In particular, the phase transformation from $\alpha-\mathrm{Si}_{3} \mathrm{~N}_{4}$ to $\beta-\mathrm{Si}_{3} \mathrm{~N}_{4}$ and the Ostwald ripening of the $\beta-\mathrm{Si}_{3} \mathrm{~N}_{4}$ grains occurs during the solution-precipitation process.

During the sintering process, the dimensions of the green body change because of densification. Therefore, controlling the liquid phase sintering behavior is important for preventing unnecessary sample deformation as well as the failure of the product and to obtain near-net shapes. Su and Johnson have proposed a theory for the master sintering curve (MSC). ${ }^{22)}$ Based on this theory, a unique MSC corresponding to densification and independent of the heating profile can be obtained from the shrinkage curves measured at various heating rates. This theory assumes that solid-state sintering, which is a primary densification process, occurs during sintering and that abnormal grain growth does not. Further, this theory has been applied in the case of various ceramics. ${ }^{23)-26)}$ In addition, the degree of sintering shrinkage can be controlled on the basis of the MSC. ${ }^{27)}$ An MSC theory

$\dagger$ Corresponding author: J. Tatami; E-mail: tatami@ynu.ac.jp

* Preface for this article: Dol http://dx.doi.org/10.2109/jcersj2.124.P4-1 analogous to that for solid-state sintering has been proposed for liquid phase sintering. This theory, too, has been applied in the case of many different materials made by liquid phase sintering. ${ }^{28)-32)}$ However, its exact form has not yet been derived. In order to do so, several controlling steps of the liquid phase sintering process have to be considered. For instance, the grain rearrangement process and the solution-precipitation process are controlled by the diffusion rate and the interfacial reaction. ${ }^{33)}$ In this study, we proposed a new MSC theory for liquid phase sintering and applied it to analyze the sintering shrinkage behaviors of $\mathrm{Si}_{3} \mathrm{~N}_{4}$ ceramics formed by adding different sintering aids.

\section{Theory}

\subsection{MSC for grain rearrangement}

In the initial stage of the liquid phase sintering process, grain rearrangement occurs owing to capillary pressure. It is known that the capillary pressure, $\Delta P$, results in the presence of the liquid between the two parallel plates forming the capillary:

$$
\Delta P=\frac{2 \gamma_{\mathrm{LV}} \cos \theta}{d}
$$

where $d$ is the space between the two plates. Further, $\gamma_{\mathrm{LV}}$ and $\theta$ are the surface energy and contact angle, respectively; these depend on not only the nature of the liquid phase but also the temperature. For this stage, the changes in the geometry of the grains need not be considered. It has been reported that the shrinkage rate attributable to the grain rearrangement caused by the capillary pressure can be calculated as follows: ${ }^{34)}$

$$
-\frac{d L}{L d t}=\frac{\Delta P \delta}{G \eta}=\frac{d \rho}{3 \rho d t}
$$

where $L$ is the instantaneous length of the sample, $t$ is the time, $\delta$ is the width of the liquid phase, $G$ is the grain size, $\eta$ is the viscosity, and $\rho$ is the relative density. In the case of Andrade- 
type viscous flow, the temperature dependency of the viscosity can be expressed as follows:

$$
\eta=\frac{k_{\mathrm{B}} T}{A} \exp \left(\frac{Q}{R T}\right)
$$

where $k_{\mathrm{B}}$ is the Boltzmann constant, $A$ is a constant, $Q$ is the activation energy of viscosity, $R$ is the gas constant, and $T$ is the temperature. Assuming that the temperature dependency of $\gamma_{\mathrm{LV}}$ and $\cos \theta$ is the Arrhenius type, the following equation can be obtained by combining the ones given above:

$$
\frac{d \rho}{3 \rho d t}=\frac{K_{\mathrm{gr}} \delta A}{G k_{\mathrm{B}} T} \exp \left(-\frac{Q_{\mathrm{gr}}}{R T}\right)
$$

Where $K_{\mathrm{gr}}$ is a constant including the effect of the viscosity, the surface energy and the contact angle, and $Q_{\mathrm{gr}}$ is the apparent activation energy of grain rearrangement process. By separation of variation and integration,

$$
\frac{k_{\mathrm{B}}}{3 K_{\mathrm{gr}} \delta A G} \int_{\rho_{0}}^{\rho} \frac{d \rho}{\rho}=\int_{0}^{\mathrm{t}} \frac{1}{T} \exp \left(-\frac{Q_{\mathrm{gr}}}{R T}\right) d t
$$

The left-hand side of Eq. (5) is a function of the density as follows:

$$
\Phi_{\mathrm{gr}}(\rho) \equiv \frac{k_{\mathrm{B}}}{3 K_{\mathrm{gr}} \delta A G} \int_{\rho_{0}}^{\rho} \frac{d \rho}{\rho}
$$

The right-hand side of Eq. (5) is a function of $Q$ as well as of the time and temperature (it is a standardized firing profile) as follows:

$$
\Theta(t, T) \equiv \int_{0}^{t} \frac{1}{T} \exp \left(-\frac{Q}{R T}\right) d t
$$

This results in the following equation:

$$
\Phi_{\mathrm{gr}}(\rho)=\Theta(t, T)
$$

This relationship indicates that the MSC for liquid phase sintering is theoretically similar to that for solid-state sintering. ${ }^{22)}$

\subsection{MSC for solution-precipitation process}

In the solution-precipitation stage, the rate of densification is controlled by two mass transfer processes, namely, diffusion and the interfacial reaction. Furthermore, it is assumed that the geometry of the grains changes, because a solution is formed at the contact area between particles, and precipitation occurs outside the contact area. In this study, a new MSC theory was proposed based on a combined sintering model ${ }^{35)}$ in a manner similar to that for the MSC theory for solid state sintering, ${ }^{22}$ while taking into account the model used by Kingery for liquid phase sintering. ${ }^{33)}$

When spherical particles come in contact because of the capillary pressure of the liquid phase, a negative pressure, $P^{0}$, acts on the pores:

$$
P^{0}=-\frac{2 \gamma_{\mathrm{LV}}}{r_{\mathrm{p}}}
$$

where $r_{\mathrm{p}}$ is the pore radius. This pressure results in a compressive stress on the particles in the contact area. The increase in the chemical potential or activity because of the pressure can be expressed as follows: ${ }^{33)}$

$$
\begin{aligned}
& \mu-\mu_{0}=k_{\mathrm{B}} T \ln \frac{a}{a_{0}}=\Delta \Pi \Omega_{\mathrm{a}} \\
& \ln \frac{a}{a_{0}} \approx \ln \frac{C}{C_{0}}=\frac{k_{1} \gamma_{\mathrm{LV}} \Omega_{\mathrm{a}}}{r_{\mathrm{p}} k_{\mathrm{B}} T}
\end{aligned}
$$

where $\mu$ and $\mu_{0}$ are the chemical potentials at the contact area and the free surface, respectively; $a$ and $a_{0}$ are activities of the contact area and the precipitation region, respectively; $\Delta \Pi$ is the capillary pressure between the contact surface and the free region; $C$ and $C_{0}$ are the concentrations of the material under consideration in the contact area and the precipitation region, respectively; $k_{1}$ is a constant; $\gamma_{\mathrm{LV}}$ is the energy of the interface between the gas and liquid phases; $\Omega_{\mathrm{a}}$ is the atomic volume; and $r_{\mathrm{p}}$ is the radius of the pores. Further, $r_{\mathrm{p}}$ can be expressed using scale factor $C_{\mathrm{p}}$ as follows:

$$
r_{\mathrm{p}}=C_{\mathrm{p}} G
$$

In the case of diffusion rate control, the diffusion flux out of a circular contact area along the circumference can be described using Fick's first law.

$$
j_{\text {asd }}=\frac{D}{\Omega} \frac{\left(C-C_{0}\right)}{\lambda}
$$

where $D$ is the diffusion coefficient. The diffusion distance of the atoms from the solution to the precipitate, $\lambda$, can be expressed using $G$ and $C_{\lambda}$ as follows:

$$
\lambda=C_{\lambda} G
$$

The concentration gradient can be expressed as follows:

$$
\frac{C-C_{0}}{\lambda}=\frac{C_{0}}{\lambda}\left(\frac{C}{C_{0}}-1\right) \approx \frac{C_{0} k_{1} \gamma_{\mathrm{LV}} \Omega_{\mathrm{a}}}{C_{\mathrm{p}} C_{\lambda} G^{2} k_{\mathrm{B}} T}
$$

Therefore, the diffusion flux in the contact area, $j_{\text {asd }}$, is the following:

$$
j_{\mathrm{asd}}=\frac{C_{0} D k_{1} \gamma_{\mathrm{LV}}}{C_{\mathrm{p}} C_{\lambda} G^{2} k_{\mathrm{B}} T}
$$

In the case of interfacial-reaction control, the diffusion flux out of the contact region, $j_{\text {asr }}$, can be determined by assuming that it is proportional to the difference in the activities of the solid between the contact area and the neighborhood and that in the precipitation region as follows:

$$
j_{\text {asr }}=\frac{k_{2}}{\Omega_{\mathrm{a}}}\left(a-a_{0}\right)
$$

where $k_{2}$ is a constant related to the interfacial reaction. Using Eqs. (3) and (9), one can derive $j_{\text {asr }}$ :

$$
j_{\text {asr }}=\frac{k_{2}}{\Omega_{\mathrm{a}}}\left[\exp \left(\frac{k_{1} \gamma_{\mathrm{LV}} \Omega_{\mathrm{a}}}{r_{\mathrm{p}} k_{\mathrm{B}} T}\right)-1\right] \approx \frac{k_{1} k_{2} \gamma_{\mathrm{LV}}}{C_{\mathrm{p}} G k_{\mathrm{B}} T}
$$

Equations (16) and (18) represent the normalized flux of the atoms arriving at the surface of the generalized pore in a manner similar to that used in Ref 35.

The total atomic diffusion flux, $J$, for any element is

$$
J=\int_{\mathrm{S}} j_{\text {as }} d A
$$

This integral can be calculated by multiplying the average local flux for diffusion-rate control, $j_{\text {asd }}$, and that for interfacial-reaction control, $j_{\text {asr }}$, by the area available for the diffusion of the atoms, if the diffusion distance and the curvatures are uniform or if it possible to approximate them using their respective average values.

$$
J=\frac{1}{2} j_{\text {asd }} \delta L_{\mathrm{d}}+j_{\text {asr }} A_{\mathrm{r}}
$$

where $(1 / 2) \delta L_{\mathrm{d}}$ and $A_{r}$ are the areas corresponding to diffusionrate and interfacial-reaction control, respectively. Further, $\delta$ is the 
thickness of the liquid phase at the contact area, $L_{\mathrm{d}}$ is the total length of the intersection between the contact area and the pore, and $A_{\mathrm{r}}$ is the area of the concave curvature. Although $L_{\mathrm{d}}$ and $A_{\mathrm{r}}$ are unknown and generally difficult to estimate, they can be expressed using $G$ and $G^{2}$ in the case of any microstructure as follows:

$$
\begin{aligned}
& \frac{1}{2} L_{\mathrm{d}}=C_{\mathrm{d}} G \\
& A_{\mathrm{r}}=C_{\mathrm{r}} G^{2}
\end{aligned}
$$

where $C_{\mathrm{d}}$ and $C_{\mathrm{r}}$ are the scaling factors, which should be valid when the microstructure is self-similar. Further, they are not always constant during sintering.

In order to relate the diffusion of the atoms to the shrinkage of the sintered body, in this study, we used the polyhedral model developed by DeHoff; ${ }^{36}$ ) this model is the same as that used for the MSC theory for solid-state sintering. In the model, the polyhedron consists of flat surfaces, and each cell is divided into a number of pyramids. As a result, the densification rate could be derived in a manner similar to that in the case of the MSC theory for solid-state sintering:

$$
\frac{d V}{V d t}=-\frac{d \rho}{\rho d t}=-\frac{3 J \Omega_{\mathrm{a}}}{h S^{\mathrm{b}}}=-\frac{3 J \Omega_{\mathrm{a}}}{C_{\mathrm{h}} C_{\mathrm{a}} G^{3}}
$$

where $h$ and $S^{\mathrm{b}}$ are the height of the pyramids and the contact area, respectively. In addition, $C_{\mathrm{h}}(=h / G)$ and $C_{\mathrm{a}}\left(=S^{\mathrm{b}} / G^{2}\right)$ are the scaling factors. By substituting Eqs. (16), (18), (20), (21), and (22) into Eq. (23), we get

$$
\frac{d \rho}{\rho d t}=\frac{3 \gamma_{\mathrm{LV}} C_{0} \Omega_{\mathrm{a}}}{k_{\mathrm{B}} T}\left(\frac{\delta D \Gamma_{\mathrm{d}}}{G^{4}}+\frac{k_{2} \Gamma_{\mathrm{r}}}{G^{2}}\right)
$$

where

$$
\begin{aligned}
& \Gamma_{\mathrm{d}}=\frac{k_{1} C_{\mathrm{d}}}{C_{\mathrm{p}} C_{\lambda} C_{\mathrm{h}} C_{\mathrm{a}}} \\
& \Gamma_{\mathrm{r}}=\frac{k_{1} C_{\mathrm{r}}}{C_{\mathrm{p}} C_{\mathrm{h}} C_{\mathrm{a}}}
\end{aligned}
$$

In the case of isotropic shrinkage, the densification rate can be converted into the linear shrinkage rate as follows:

$$
-\frac{d L}{L d t}=\frac{d \rho}{3 \rho d t}
$$

If a single mechanism is dominant during the sintering process, Eq. (24) can be simplified to

$$
\frac{d \rho}{\rho d t}=\frac{3 \gamma_{\mathrm{LV}} C_{0} \Omega_{\mathrm{a}} K_{0} \Gamma(\rho)}{k_{\mathrm{B}} T[G(\rho)]^{\mathrm{n}}} \exp \left(-\frac{Q}{R T}\right)
$$

In the case of diffusion-rate control, $\mathrm{Q}$ is the activation energy for the diffusion of the solid through the liquid phase and should be the same as the viscosity of the liquid phase. Further, $K_{0}=$ $\delta D_{\mathrm{d}}$ and $n=4$. For interfacial-reaction control, Q is the activation energy for the interfacial reaction. Further, $K_{0}=k_{2}$ and $n=2$. In the case of this equation, $G$ and $\Gamma$ are assumed to be functions only of the density. By separating the variables and integrating the equation, we get the following:

$$
\frac{k_{\mathrm{B}}}{3 \gamma_{\mathrm{LV}} C_{0} \Omega_{\mathrm{a}} K_{0}} \int_{\rho_{0}}^{\rho} \frac{[G(\rho)]^{\mathrm{n}}}{\rho \Gamma(\rho)} d \rho=\int_{0}^{\mathrm{t}} \frac{1}{T} \exp \left(-\frac{Q}{R T}\right) d t
$$

The left-hand side of Eq. (29) is a function of the density, microstructure, and material properties (the exception is the activation energy of sintering) as follows:

$$
\Phi_{\mathrm{sp}}(\rho) \equiv \frac{k_{\mathrm{B}}}{3 \gamma_{\mathrm{LV}} C_{0} \Omega_{\mathrm{a}} K_{0}} \int_{\rho_{0}}^{\rho} \frac{[G(\rho)]^{\mathrm{n}}}{\rho \Gamma(\rho)} d \rho
$$

The right-hand side of Eq. (29) is a function of $Q$ as well as the time and temperature - this suggests a standardized firing profile:

$$
\Theta(t, T) \equiv \int_{0}^{t} \frac{1}{T} \exp \left(-\frac{Q}{R T}\right) d t
$$

Consequently, the following equation is obtained:

$$
\Phi_{\mathrm{sp}}(\rho)=\Theta(t, T)
$$

This relationship indicates that the MSC for liquid phase sintering is the same that for solid-state sintering. The MSC can be plotted

\section{Experimental procedure}

Very fine high-purity powders of $\mathrm{Si}_{3} \mathrm{~N}_{4}$ (Ube Industries. Ltd., E-10), $\mathrm{Y}_{2} \mathrm{O}_{3}$ (Shinetsu Chemical Co., Ltd., RU), $\mathrm{Al}_{2} \mathrm{O}_{3}$ (Sumitomo Chemical Co., Ltd., AKP-30), AlN (Tokuyama Corp., F-Grade), and $\mathrm{TiO}_{2}$ (Sakai Chemical Industry Co. Ltd., $\mathrm{R}-11 \mathrm{P})$ were used as the raw materials. The compositions of the various batches are listed in Table 1. The raw materials were mixed in ethanol by ball milling along with $2 \mathrm{wt} \%$ dispersant (Seruna E503, Chukyoyushi Co., Japan). After the ethanol had been removed, $4 \mathrm{wt} \%$ paraffin (melting point $46-48^{\circ} \mathrm{C}$, Junsei Chemical Co., Japan) and 2 wt \% Bis(2-ethyhexyl) phthalate (Wako Junyaku Co., Japan) were added as the binder and lubricant, respectively. The powder mixtures were molded into specimens with a diameter of $15 \mathrm{~mm}$ and length of $7 \mathrm{~mm}$ by uniaxial pressing and cold isostatic pressing. The green bodies were dewaxed at $500^{\circ} \mathrm{C}$ in air. The degree of sintering shrinkage was measured in-situ directly using a dilatometer equipped with a gas pressure furnace (Himulti 5000, Fujidenpa Kogyo Co., Japan), in keeping with previous studies. ${ }^{37), 38)}$ This apparatus calculates the degree of sintering shrinkage of the test sample on the basis of the difference in the displacement of the sample with respect to a reference carbon rod. A BN plate was used to prevent the sample and the carbon rod from reacting with each other. The maximum temperature was $1800^{\circ} \mathrm{C}$, the soaking time was $2 \mathrm{~h}$, and the firing atmosphere was $0.9 \mathrm{MPa} \mathrm{N} \mathrm{N}_{2}$. In order to determine the MSC, the heating rate was varied from 10 to $30^{\circ} \mathrm{C} / \mathrm{min}$.

\section{Results and discussion}

Figure 1(a) shows the sintering shrinkage curves of $\mathrm{Si}_{3} \mathrm{~N}_{4}$ ceramics produced using different sintering aids. The curves were measured at a heating rate of $10^{\circ} \mathrm{C} / \mathrm{min}$. Although all the samples started shrinking at almost the same temperature $\left(\sim 1350^{\circ} \mathrm{C}\right)$ and exhibited the same final shrinkage ratio (approximately 20\%), their shrinkage behaviors varied with the sintering aid used. Figure 1(b) shows the shrinkage rates as calculated from the experimental data shown in Fig. 1(a). Three peaks were observed in the case of all the samples. The first peak was observed at approximately $1500^{\circ} \mathrm{C}$. In a previous study, we had observed that the $\alpha$-to- $\beta$ phase transformation of $\mathrm{Si}_{3} \mathrm{~N}_{4}$ commenced at temper-

Table 1. Batch compositions (weight ratio) of the samples used to evaluate the sintering shrinkage behaviors of $\mathrm{Si}_{3} \mathrm{~N}_{4}$ ceramics

\begin{tabular}{cccccc}
\hline Sample & $\mathrm{Si}_{3} \mathrm{~N}_{4}$ & $\mathrm{Y}_{2} \mathrm{O}_{3}$ & $\mathrm{Al}_{2} \mathrm{O}_{3}$ & $\mathrm{TiO}_{2}$ & $\mathrm{AlN}$ \\
\hline 0T0A & 92 & 5 & 3 & 0 & 0 \\
5T0A & 92 & 5 & 3 & 5 & 0 \\
0T5A & 92 & 5 & 3 & 0 & 5 \\
5T5A & 92 & 5 & 3 & 5 & 5 \\
\hline
\end{tabular}


atures higher than $1500^{\circ} \mathrm{C}$ and finished at temperatures equal to or higher than $1800^{\circ} \mathrm{C}$; this was true for all the samples. ${ }^{37)}$ Therefore, the three peaks in Fig. 1(b) were considered to be related to grain rearrangement, solution-precipitation, and Ostwald ripening, respectively. On comparing Figs. 1(a) and 1(b), it can be seen that the grain rearrangement occurred when the shrinkage ratio was lower than $2 \%$. This was followed by solution-precipitation, which occurred when the ratio was between 2 and $18 \%$.

Figure 2 shows the shrinkage ratios measured at different heating rates. The temperature at which shrinkage started increased and the shrinkage ratio decreased with an increase in

(a)

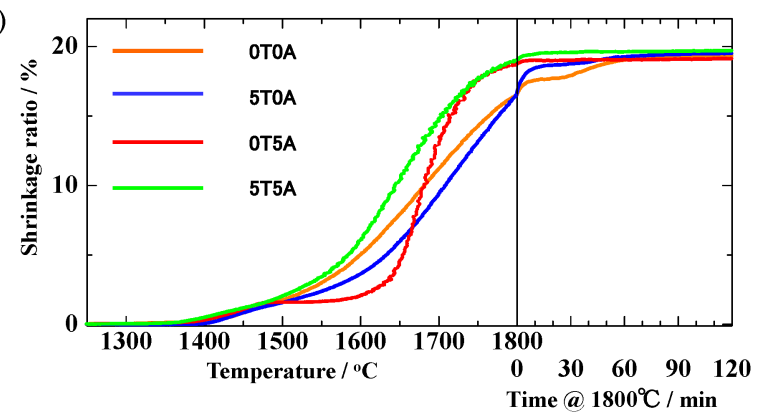

(b)

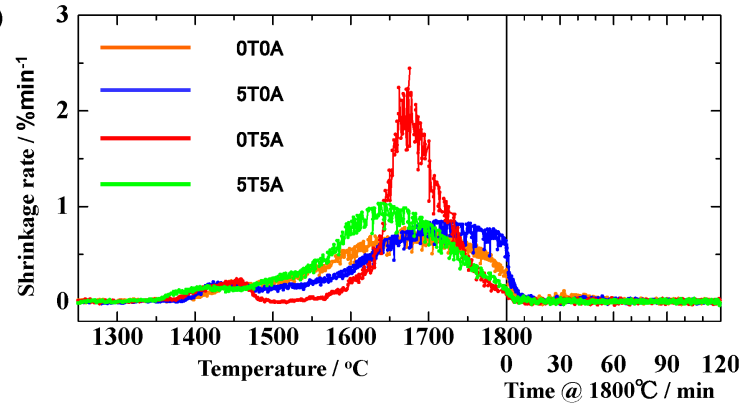

Fig. 1. (a) Shrinkage ratios and (b) shrinkage rates of $\mathrm{Si}_{3} \mathrm{~N}_{4}$ ceramics produced using different sintering aids.

(a)

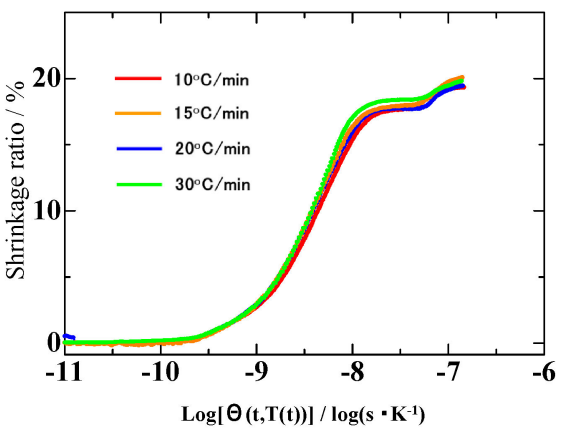

(c)

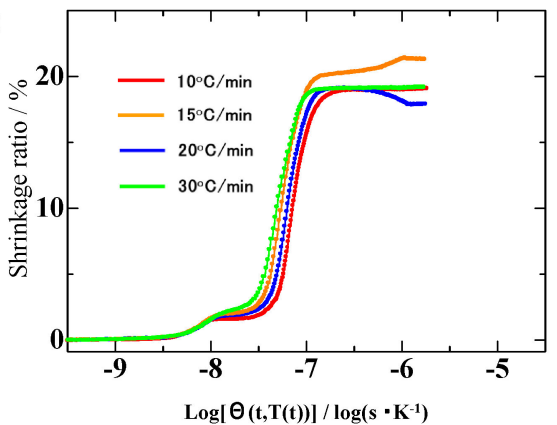

the heating rate; again, this was the case for all the samples. The MSC was obtained by minimizing the square of the residual error of $\Theta(t, T)$ for the same shrinkage ratio for different heating rates; this was done by varying the activation energy, $Q$, as was done in a previous study on the solid-state sintering of $\mathrm{Al}_{2} \mathrm{O}_{3}{ }^{27)} \Theta(\mathrm{t}, \mathrm{T})$ was estimated from the numerical calculation of the integral in Eqs. (7) and (31) using the time-temperature relationship and the activation energy. In order to obtain the MSC, the specific values of the parameters in the Eqs. (6) and (30), such as $A, G, \gamma_{\mathrm{LV}}, \mathrm{C}_{0}$, $\mathrm{K}_{0}$, are not used as is the case with the previous study. ${ }^{22)-26)}$ Furthermore, the MSC was separately estimated using the shrinkage ratio data of $0-2,2-15 \%$, and over $15 \%$, respectively.

Figures 3(a) and 4(a) show the MSC of sample 0T0A. The MSC was obtained for ratios of $0-2 \%$ [Fig. 3(a)] and 2-15\% [Fig. 4(a)], with the activation energies being 294 and 345 $\mathrm{kJ} / \mathrm{mol}$, respectively. This meant that the apparent activation energies of sintering by grain rearrangement and solutionprecipitation were 294 and $345 \mathrm{KJ} / \mathrm{mol}$, respectively, for sample 0T0A. As shown in Figs. 3(b)-3(d) and Figs. 4(b)-4(d), the MSCs corresponding to grain rearrangement and the solutionprecipitation process were obtained for all the samples. However, the MSCs could not be obtained for ratios greater than $15 \%$.

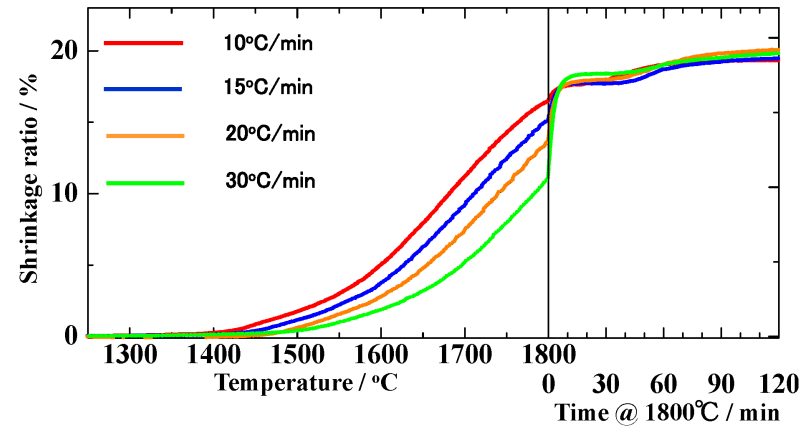

Fig. 2. Shrinkage ratios of sample $0 \mathrm{~T} 0 \mathrm{~A}$ when fired at various heating rates.

(b)

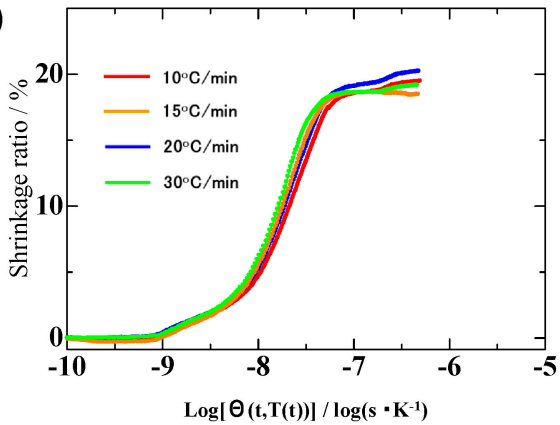

(d)

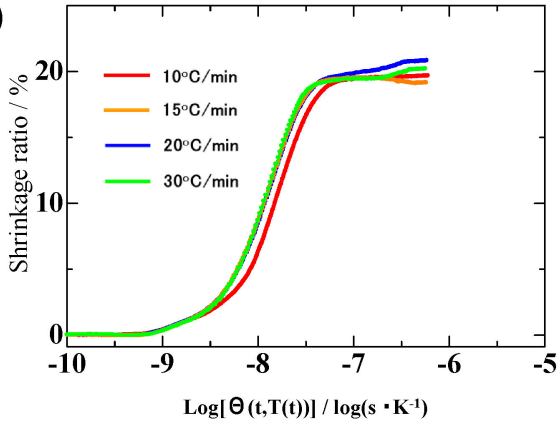

Fig. 3. MSCs of the $\mathrm{Si}_{3} \mathrm{~N}_{4}$ ceramics for shrinkage ratios of 0-2\%: (a) $0 \mathrm{~T} 0 \mathrm{~A}$, (b) $5 \mathrm{~T} 0 \mathrm{~A}$, (c) $0 \mathrm{~T} 5 \mathrm{~A} 1$, and (d) $5 \mathrm{~T} 5 \mathrm{~A}$. 
(a)

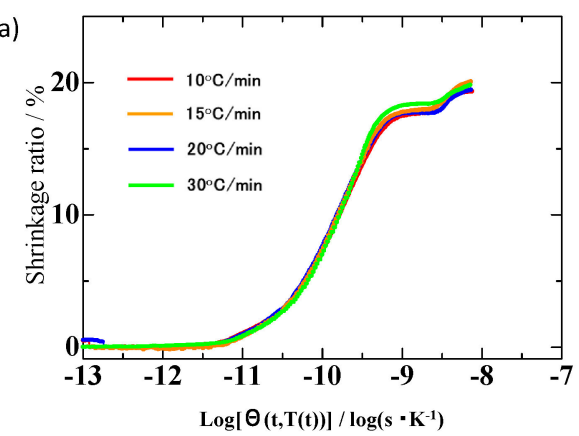

(c)

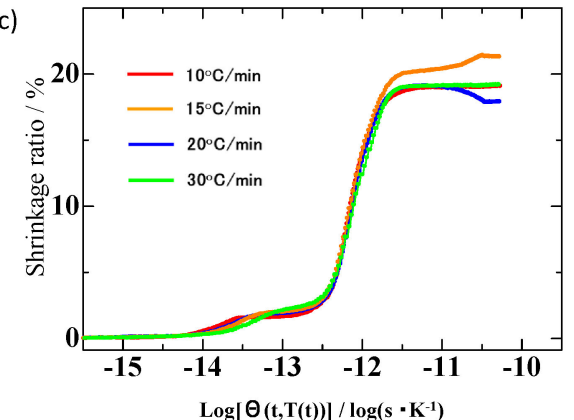

(b)

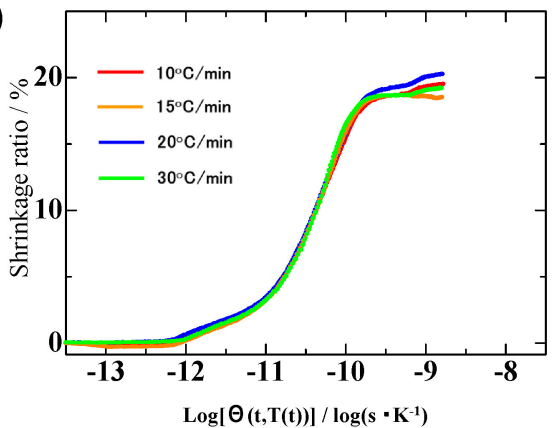

(d)

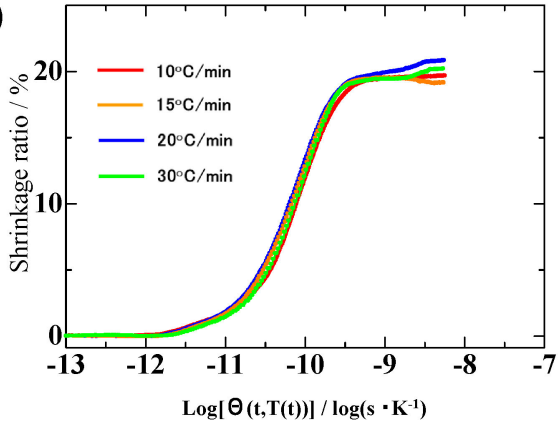

Fig. 4. MSCs of the $\mathrm{Si}_{3} \mathrm{~N}_{4}$ ceramics for shrinkage ratios of 2-15\%: (a) 0T0A, (b) 5T0A, (c) 0T5A, and (d) 5T5A.

(a)

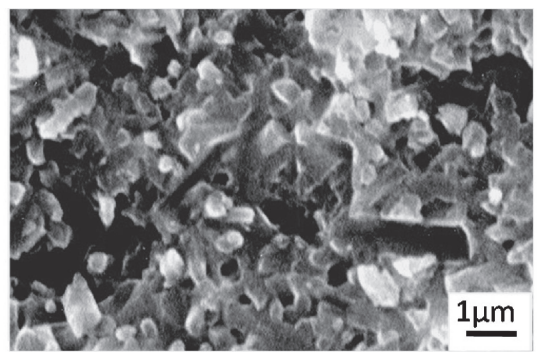

(b)

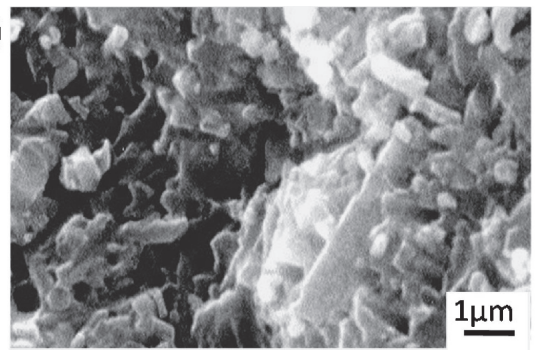

Fig. 5. SEM images of sample $0 \mathrm{~T} 0 \mathrm{~A}$, which was fired at $1800^{\circ} \mathrm{C}$ for $120 \mathrm{~min}$ at heating rates of 10 and $30^{\circ} \mathrm{C} / \mathrm{min}$.

Table 2. Apparent activation energies of sintering of the $\mathrm{Si}_{3} \mathrm{~N}_{4}$ ceramics (unit: $\mathrm{kJ} / \mathrm{mol}$ )

\begin{tabular}{ccc}
\hline \multirow{2}{*}{ Sample } & \multicolumn{2}{c}{ Range of shrinkage ratios } \\
\cline { 2 - 3 } & $0-2 \%$ & $2-15 \%$ \\
\hline 0T0A & 294 & 345 \\
5T0A & 273 & 371 \\
0T5A & 251 & 430 \\
5T5A & 270 & 350 \\
\hline
\end{tabular}

Figure 5 shows SEM images of sample 0T0A, which was fired at $1800^{\circ} \mathrm{C}$ for $120 \mathrm{~min}$ at heating rates of 10 and $30^{\circ} \mathrm{C} / \mathrm{min}$. Significantly elongated grains of $\beta-\mathrm{Si}_{3} \mathrm{~N}_{4}$ were observed. Further, the microstructure depended on the heating rate used. In addition, it has been reported that the growth of elongated grains can lead to the expansion of the sintered body. ${ }^{39)}$ It is for this reason that the MSC could not be measured for shrinkage ratios greater than $15 \%$.

Table 2 lists the apparent activation energies of sintering of the $\mathrm{Si}_{3} \mathrm{~N}_{4}$ ceramics, which were approximately $250-290$ and 350$430 \mathrm{~kJ} / \mathrm{mol}$ for grain rearrangement and the solution-precipitation process, respectively. The apparent activation energy of sintering of $\mathrm{Si}_{3} \mathrm{~N}_{4}$ for grain rearrangement also depended slightly on the sintering aid used. Abe has reported that the activation energy for the initial stage of sintering of $\mathrm{Si}_{3} \mathrm{~N}_{4}$ is $244.0 \mathrm{~kJ} / \mathrm{mol}{ }^{40)}$ The apparent activation energies determined in the present study were almost similar to those reported by Abe, even though the sintering aids used in the two studies had different compositions.

The apparent activation energy of sintering for the solutionprecipitation process has been reported by a number of researchers. $^{41)-47)}$ The value (approximately $350 \mathrm{~kJ} / \mathrm{mol}$ ) determined during a grain growth study ${ }^{41)}$ was relatively low. However, the apparent activation energy estimated in the present study was almost similar. The diffusion of nitrogen through the oxynitride liquid phase is believed to result in a higher activation energy, because the number of chemical bonds in nitrogen is greater than that of the bonds in oxygen. The nitrogen content of the liquid phase can be increased by adding AlN. Furthermore, TiN is formed during the sintering of $\mathrm{Si}_{3} \mathrm{~N}_{4}$, owing to a reaction between $\mathrm{TiO}_{2}$ and AlN. ${ }^{37)}$ As a result, the apparent activation energy of sample 0T5A was higher than those of the other samples.

\section{Conclusions}

The MSC theory was extended to liquid phase sintering for grain rearrangement and the solution-precipitation process. The sintering behaviors of $\mathrm{Si}_{3} \mathrm{~N}_{4}$ powder compacts were observed directly using a dilatometer. Further, the MSC theory was applied to determine the validity of the experimentally obtained sintering 
shrinkage ratios. The MSCs of the $\mathrm{Si}_{3} \mathrm{~N}_{4}$ ceramics corresponding to grain rearrangement and the solution-precipitation process were measured; these were related to shrinkage ratios of $0-2$ and $2-15 \%$, respectively. Finally, the activation energies corresponding to grain rearrangement and the solution-precipitation process were $251-294$ and $345-430 \mathrm{~kJ} / \mathrm{mol}$, respectively, depending on the sintering aid used.

\section{References}

1) G. C. Deeley, J. M. Herbert and N. C. Moore, Pow.Met., 8, 145-151 (1961).

2) K. Komeya and F. Noda, "Aluminum Nitride and Silicon Nitride for High Temperature Gas Turbine Engines", SAE Paper No. 740237 (1974).

3) M. Mitomo, J. Mater. Sci., 11, 1103-1107 (1976).

4) G. R. Terwillinger and F. F. Lange, J. Mater. Sci., 10, 11691174 (1975).

5) K. Komeya, M. Komatsu, T. Kameda, Y. Goto and A. Tsuge, J. Mater. Sci., 26, 5513-5516 (1991).

6) M. Matsuoka, J. Tatami, T. Wakihara, K. Komeya and T. Meguro, J. Asian Ceram. Soc., 2, 199-203 (2014).

7) I.-W. Chen and A. Rosenflanz, Nature, 389, 701-704 (1997).

8) S. G. Guo, N. Hirosaki, Y. Yamamoto, T. Nishimura and M. Mitomo, J. Am. Ceram. Soc., 85, 1607-1609 (2002).

9) C. H. Lin, K. Komeya, T. Meguro, J. Tatami, Y. Abe and M. Komatsu, J. Ceram. Soc. Japan, 111, 452-456 (2003).

10) J. Tatami, I. W. Chen, Y. Yamamoto, M. Komastu, K. Komeya, D. K. Kim, T. Wakihara and T. Meguro, J. Ceram. Soc. Japan, 114, 1049-1053 (2006).

11) J. Tatami, E. Kodama, H. Watanabe, H. Nakano, T. Wakihara, K. Komeya, T. Meguro and A. Azushima, J. Ceram. Soc. Japan, 116, 749-754 (2008).

12) H. Kawamura and S. Yamamoto, "Improvement of Diesel Engine Startability by Ceramic Glow Plug Start System", SAE Paprer No. 830580 (1983)

13) S. Kamiya, M. Murachi, H. Kawamoto, S. Kato, S. Kawakami and Y. Suzuki, "Silicon Nitride Swirl Chambers for High Power Charged Diesel Engines", SAE No. 850523 (1985).

14) K. Komeya and H. Kotani, JSAE Rev., 7, 72-79 (1986).

15) K. Kijima and S. Shirasaki, J. Chem. Phys., 65, 2668-2671 (1976).

16) A. Tsuge, K. Nishida and M. Komatsu, J. Am. Ceram. Soc., 58, 323-326 (1975).

17) K. Komeya, Am. Ceram. Soc. Bull., 63, 1158-1159, 1164 (1984).

18) S. Watanabe, T. Kodera and T. Ogihara, J. Ceram. Soc. Japan, 123, 345-350 (2015).

19) S. K. Choi, S. W. Ui, I. S. Choi and S. C. Choi, J. Ceram. Soc. Japan, 122, 198-203 (2014).

20) Q. H. Yang, H. P. Wang, Z. P. He, D. H. Li, Q. H. Wang and S. Q. Xu, J. Ceram. Soc. Japan, 122, 125-128 (2014).

21) T. Shimonosono, S. Ikeyama, Y. Hirata and S. Sameshima, J. Asian Ceram. Soc., 2, 422-428 (2014).

22) H. Su and D. L. Johnson, J. Am. Ceram. Soc., 79, 3211-3217 (1996).
23) A. J. Rayner, R. M. C. Clemmer and S. F. Corbin, J. Am. Ceram. Soc., 98, 1060-1065 (2015).

24) V. Pouchly, K. Maca and Z. J. Shen, J. Eur. Ceram. Soc., 33, 2275-2283 (2013).

25) K. G. Ewsuk, D. T. Ellerby and C. B. DiAntonio, J. Am. Ceram. Soc., 89, 2003-2009 (2006).

26) M. Mazaheri, A. Simchi, M. Dourandish and F. Golestani-Fard, Ceram. Int., 35, 547-554 (2009).

27) J. Tatami, Y. Suzuki, T. Wakihara, T. Meguro and K. Komeya, Key Eng. Mater., 317-318, 11-14 (2006).

28) R. Bollina, S. J. Park and R. M. German, POWDER METALLURGY, 53, 20-26 (2010).

29) D. Choron, S. Marinel, B. Pintault, S. Beaudet-Savignat and R. Macaigne, J. Eur. Ceram. Soc., 35, 4195-4202 (2015).

30) K. Rozenburg, I. E. Reimanis, H. J. Kleebe and R. L. Cook, J. Am. Ceram. Soc., 91, 444-450 (2008).

31) S. J. Park, R. M. German, J. M. Martin, J. F. Guo and J. L. Johnson, Metall. Mater. Trans., A, 37, 2837-2848 (2006).

32) L. Wang, V. Pouchly, K. Maca, Z. J. Shen and Y. Xiong, J. Asian Ceram. Soc., 3, 183-187 (2015).

33) W. D. Kingery, J. Appl. Phys., 30, 301-306 (1959).

34) R. M. German, "Liquid Phase Sintering", Plemium, New York (1985) p. 74

35) J. D. Hansen, R. P. Rusin, M.-H. Teng and D. L. Johnson, J. Am. Ceram. Soc., 75, 1129-1135 (1992).

36) R. T. DeHoff, "A Cell Model for Microstructural Evolution during Sintering", in Material Science Research, Vol. 16, Sintering and Heterogeneous Catalysis, Ed. by G. C. Kuczynski, A. E. Miller and G. A. Sargent, Plenum Press, New York (1984) pp. 23-34.

37) J. Tatami, M. Toyama, K. Noguchi, K. Komeya, T. Meguro and M. Komatsu, Ceram. Trans., 247, 83-86 (2003).

38) T. Wakihara, M. Yabuki, J. Tatami, K. Komeya, T. Meguro, H. Hyuga and H. Kita, J. Am. Ceram. Soc., 91, 3413-3415 (2008).

39) K. Koga, Ceramics, 25, 107-111 (1990).

40) O. Abe, J. Mater. Sci., 25, 4018-4026 (1990).

41) M. Mitomo, M. Tsutsumi, H. Tanaka, S. Uenosono and F. Saito, J. Am. Ceram. Soc., 73, 2441-2445 (1990).

42) L. J. Bowen, R. J. Weston, T. G. Carruthers and J. Brook, J. Mater. Sci., 13, 341-350 (1978).

43) K. H. Jack, "The Role of Additives in the Densification of Nitrogen Ceramics", in Final Technical Report, DAERO-78-G012. European Research Office, U.S. Army, London (1978) pp. 3-14.

44) C. M. Hwang, T. Y. Tien and I-Wei Chen, "Anisotropic Grain Growth During Final Stage Sintering of Silicon Nitride Ceramics", in Sintering, Ed. by S. Somiya, M. Shimada, M. Yoshimura, and R. Watanabe. Elsevier Applied Science, London (1988) pp. 1034-1039.

45) K. R. Lai and Y. Y. Tien, J. Am. Ceram. Soc., 76, 91-96 (1993).

46) G. Ziegler, J. Heinrich and G. Wötting, J. Mater. Sci., 22, 3041-3086 (1987).

47) M. Kitayama, K. Hirao and S. Kanzaki, J. Am. Ceram. Soc., 89, 2612-2618 (2006). 